\title{
Antioxidant activity, bioactive polyphenols in Mexican goats' milk cheeses on summer grazing
}

\author{
Mario Cuchillo Hilario ${ }^{1}$, Claudia Delgadillo Puga ${ }^{1 *}$, Arturo Navarro Ocaña ${ }^{2}$ \\ and Fernando Pérez-Gil Romo ${ }^{1}$ \\ ${ }^{1}$ Departamento de Nutrición Animal, Instituto Nacional de Ciencias Médicas y Nutrición Salvador Zubiran (INCMNSZ), Vasco de \\ Quiroga 15, Tlalpan, CP. 14000 D.F., México. \\ ${ }^{2}$ Departamento de Alimentos y Biotecnología, Facultad de Química, Universidad Nacional Autónoma de México, Ciudad Universitaria, \\ Coyoacan, CP. 04510 D.F., México.
}

Received 27 May 2007; accepted for publication 27 July 2009; first published online 15 September 2009

\begin{abstract}
Two feeding systems trials were carried out to determine the antioxidant activity of soft goats' milk cheeses, and also to evaluate the presence of bioactive polyphenolic compounds. Two groups (A and B), each one with 20 (BW $50 \pm 5 \mathrm{~kg}$ ) French Alpine goats were employed. All animals had between 70 to 80 milking days and were milked once a day. Group A included daily grazing on shruby rangeland vegetation, and group B was kept in full indoor confinement. Thirty kg of goats' milk from each group were collected; $15 \mathrm{~kg}$ from each were pasteurized and the remaining $15 \mathrm{~kg}$ were not pasteurized (raw), resulting in four treatments (two feeding system $\times$ two milk treatments). Soft goat's cheese antioxidant activity can be modified by the animals feeding system; grazing management represents a better option than indoor feeding to produce a healthy profile of bioactive compounds; providing an increase of total polyphenol, hydroxycinnamic acids and flavonoid concentrations. Pasteurization did have a significant effect on these metabolites, and diminished total polyphenol concentration. More research is needed to elucidate the potential of soft goat's cheese as a functional food.
\end{abstract}

Keywords: Grazing; indoor, milk cheese; antioxidant and bioactive compounds.

\begin{abstract}
Abbreviations: $\mathrm{GR}=$ cheese made from grazing goats' raw milk, GP=cheese made from grazing goats' pasteurized milk, IR = cheese made from indoor goats' raw milk, IP=cheese made from indoor goats' pasteurized milk. Trolox=6-hydroxy-2, 5, 7, 8-tetramethylchroman-2-carboxylic acid. $t \mathrm{BHQ}=$ Ter-butylhydroquinone, $\mathrm{DPPH}^{+}=\left(1,1\right.$-diphenyl-2-picrylhydrazyl), ABTS ${ }^{+}=\mathrm{ABTS}[2$, 2-azinobis-(3-ethylbenzothiazoline-6-sulphonic acid)].
\end{abstract}

Goats adapt well to environmental conditions in arid lands, being able to obtain an adequate diet, even when forage is scarce and they can feed over rough and otherwise inaccessible terrain. Mexican rangeland is dominated by different vegetation species, which usually contain metabolites with certain benefits for human health, including alkaloids, glycosides, fatty acids, terpenes, phenols, saponins, tannins, and flavonoids (Galina et al. 2007; Ruiz-Terán et al. 2008; Cuchillo et al. 2009a). All pasture

*For correspondence; e-mail: dpclau@quetzal.innsz.mx Proofs to: Dra CD Puga, Departamento de Nutrición Animal, Instituto Nacional de Ciencias Médicas y Nutrición Salvador Zubiran (INCMNSZ), Vasco de Quiroga 15, Tlalpan, CP. 14000 D.F., México. plants change their chemical and nutritive composition seasonally, which gives cheeses made from milk of grazing animals different nutritive properties and flavours during year round seasons, being a significant source of bioactive compounds (Sanz Sampelayo et al. 2007), metabolites that are thought to be an important part of both human and animal diets (Galina et al. 2007; Ruiz-Terán et al. 2008). Although many questions remain concerning milk functional compounds, it is well known that some compounds found in foods can diminish DNA changes that lead to the reduction of lipid and protein damage, mainly caused by the presence of free radicals. Recent research has demonstrated that fatty acids, hydroxycinnamic acids and flavonoids play a synergic antioxidant role, that by different mechanisms protect cells, against free radical damage 
(Halliwell, 1996). Milk and by-products provide a wide range of these compounds with potentially functional properties which are transferred from the animal diet (O'connell \& Fox, 2001; Cuchillo et al. 2009b; Puga et al. 2009a, b). However, a tenuous relationship has been found between forage intakes and antioxidant compounds in goat milk, particularly in flavonoids like rutin and quercetin (De Feo et al. 2006). Middleton et al. (2000) reported that quercetin is the best antioxidant of the flavonoids, five times more powerful than vitamins $\mathrm{A}$ and $\mathrm{C}$. Likewise, the pro-oxidant activities of milk have been attributed to both the thermal degradation of naturally occurring antioxidants, and the formation of novel oxidative species in the early stages the Maillard reaction (Calligaris et al. 2004). Thus, the significance of the animal diet and the metabolic pathways followed by the bioactive compounds, their final concentration in milk and dairy products and their benefits to human nutrition are important research topics. The objectives of this study were: (1) to evaluate the effects of two feed systems on cheese antioxidant activity, (2) to demonstrate in goat cheeses the presence of bioactive polyphenolic compounds and (3) to evaluate these parameters in cheese made from raw versus pasteurized goats' milk.

\section{Material and Methods}

\section{Experimental animals}

The study was conducted in Querétaro, México (latitude: $20^{\circ} 35^{\prime}$, longitude: $100^{\circ} 18^{\prime}$ ), with a climate described as dry semiarid with isolated rains in the winter, and a total of $460 \mathrm{~mm}$ average precipitation per year. Two groups (A and B) each with 20 French Alpine goats (body weight $50 \pm 5 \mathrm{~kg}$ ) were studied. All animals were milked once daily at 7:00 $\mathrm{h}$ and had been in milk for between 70 and $80 \mathrm{~d}$. Group A animals grazed 8 hours/d on 14 ha shruby rangeland after milking, with overnight confinement. The rangeland where group A grazed is characterized by the following forbs: Aristida adscensionis, Bouteloua curtipendula, B. repens, Chloris virgata, Leptochloa dubia, Lippia queretarensis, Pennisetum ciliare, Rhynchelytrum roseum, Urochloa fasciculata. Leguminous trees: Acacia farnesiana, Acacia schaffneri, Mimosa biuncifera, Prosopis laevigata and Cactus: Opuntia affasiacantha, O. amyctaea, O. hytiacantha, O. imbricata, O. robusta, O. streptacantha and O. tomentosa (Cuchillo et al. 2009a; Puga et al. 2009b). Group B was kept in full indoor confinement during the study; fed $1.5 \mathrm{~kg}$ Lucerne hay and $1 \mathrm{~kg}$ concentrate $(18 \%$ of crude protein and $2.5 \mathrm{Mcal} / \mathrm{kg})$.

\section{Cheese manufacture}

Thirty kg goats' milk were collected from each group; $15 \mathrm{~kg}$ from each group were curded from raw milk, and the rest $(15 \mathrm{~kg})$ were pasteurized $\left(63{ }^{\circ} \mathrm{C}\right.$ for $30 \mathrm{~min}$ and cooled to $40^{\circ} \mathrm{C}$ ) before cheese production. Therefore
4 kinds of cheese were made from grazing goats' raw milk (GR), from grazing goats' pasteurized milk (GP), from indoor goats' raw milk (IR), and from indoor goats' pasteurized milk (IP). Curd was prepared by adding a mix of $100 \mathrm{ml}$ whey lactic bacteria (Lactobacillus brevis; Lb. helveticus; Lb. plantarum; Lb. delbrueckii and Leuconostoc lactis) saved from the previous day and $1 \mathrm{ml}$ of a commercial rennet starter (Cuamex, Querétaro, Mexico). The milk was set at the same temperature to coagulate for $24 \mathrm{~h}$. After which, curd was scooped into cheese cloths for $72 \mathrm{~h}$; hand salted (14 g NaCl), and a moulded for $24 \mathrm{~h}$. Five parallel cheeses per treatment were kept frozen at $-80{ }^{\circ} \mathrm{C}$; before chemical analyses, the samples were thawed at $4{ }^{\circ} \mathrm{C}$.

\section{Solvent extraction of cheese sample}

The cheese sample (20 g) was extracted twice with $150 \mathrm{ml}$ hexane, then homogenized and stirred with sodium sulphate anhydrous, and the solvent evaporated; a Rotovapor at $30^{\circ} \mathrm{C}$ and $150 \mathrm{rpm}$ (Büchi R-205, Labortechnik AG, Switzerland) was used to concentrate the sample. A third extraction was carried out with methanol, then dehydrated, evaporated, and concentrated by the same procedure. The methanol extracts were frozen at $-80^{\circ} \mathrm{C}$, lyophilized and stored at $4{ }^{\circ} \mathrm{C}$ for later analysis (Labconco Freezone 6, Labconco Corp., Kansas City, MO, USA).

\section{Total phenol determination in the cheese extracts}

Total phenolic content in cheese alcoholic extracts was determined by the Folin-Ciocalteu colorimetric method described by Taga et al. (1984). The concentration was calculated using gallic acid as standard (Sigma-Aldrich), and the results were expressed as mg gallic acid equivalents (GAE) per kg extract.

\section{Quantitative determination of bioactive polyphenolic compounds by HPLC}

Twenty microlitres of extracted cheese samples were analysed by HPLC to measure the presence of flavonoids and hydroxycinnamic acids according to Carnachan \& Harris (2000). HPLC 1525 Binary Pump (Waters Milford, USA) and Symmetry $\mathrm{C}_{18}(5 \mu \mathrm{m}$ steel $3.9 \mathrm{~mm} \times 150 \mathrm{~mm}$; Waters Milford, USA) column was employed. Methanol: water (30:70), and $0 \cdot 16 \mathrm{M}$-acetic acid at $\mathrm{pH} 2 \cdot 4$, was used as a carrier at a flow rate of $1 \mathrm{ml} / \mathrm{min}$. Oven temperature was at $45{ }^{\circ} \mathrm{C}$. Each standard $(5 \mu \mathrm{g})$ : catequine $(2 \cdot 21 \mathrm{mg} / \mathrm{ml})$, quercetin $(1.25 \mathrm{mg} / \mathrm{ml})$, caffeic $(0.032 \mathrm{mg} / \mathrm{ml})$, chlorogenic $(0.033 \mathrm{mg} / \mathrm{ml})$ and ferulic acid $(0.0031 \mathrm{mg} / \mathrm{ml})$ were dissolved into methanol. A calibration curve was employed by each standard using three dilutions $(1: 1 ; 1: 3$ and $1: 5)$. Identification of the peaks was by retention times of individual standard flavonoids and hydroxycinnamic acids, using a Brezze version 6.30 Waters Software. Concentration was expressed as $\mathrm{mg} / \mathrm{kg}$ sample. All analytical 


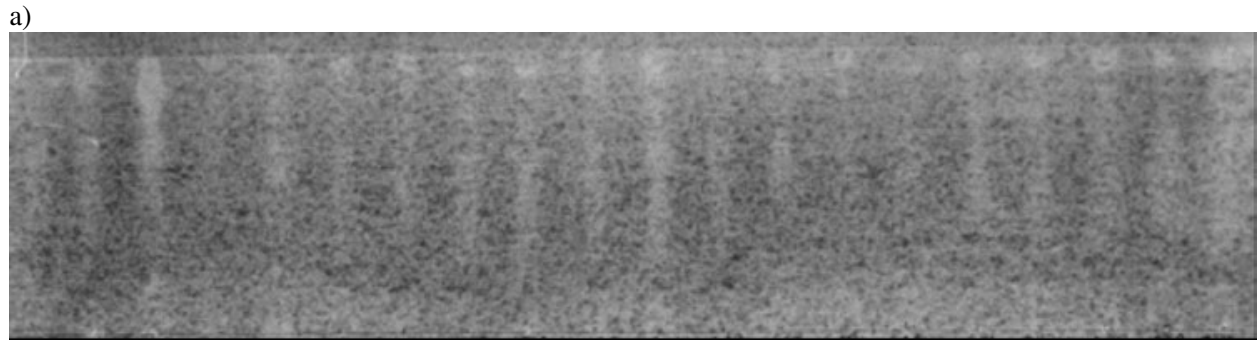

b)

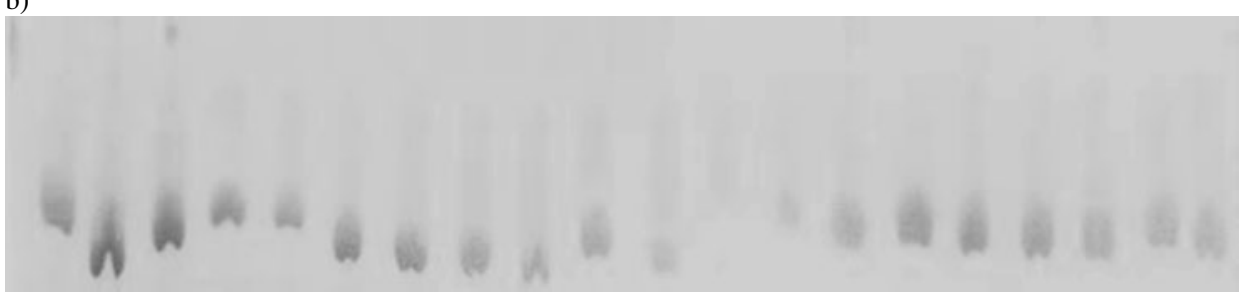

c)

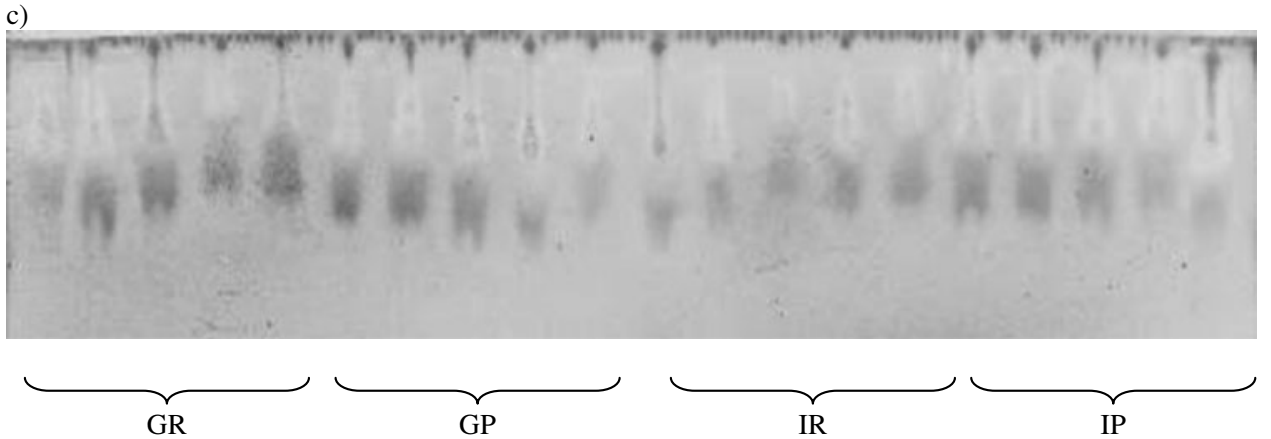

Fig. 1. Effect of feeding system on qualitative evaluation of the free-radical scavenging and bioactive polyphenols by TLC of four kinds of goats' milk cheese extracts developed by DPPH+radicalt (a), Ceric sulphate (b) and vanillin-sulphuric acid (c). GR $=$ cheese made from grazing goat's raw milk, GP=cheese made from grazing goat's pasteurized milk, IR=cheese made from indoor goat's raw milk, IP=cheese made from indoor goat's pasteurized milk.

reagents and standards were from the Sigma-Aldrich, Steinheim, Germany.

\section{Qualitative evaluation of the free-radical scavenging and bioactive polyphenols TLC}

Qualitative assays were performed as follows: a solvent system consisting of chloroform-methanol-water $(3 \cdot 5: 1 \cdot 3: 0 \cdot 2)$ was used to develop silica gel TLC plates $(10 \mathrm{~cm} \times 20 \mathrm{~cm}$; Fluka, Steinheim, Germany). Extract of samples (20 mg) were prepared in $1 \mathrm{ml}$ methanol and $10 \mu \mathrm{l}$ aliquots were applied to the plate. The chromatograms were developed at room temperature, air-dried and the spots were detected as follows:

a) Qualitative free radical scavenging activity was performed by dissolving $2 \mathrm{mg} \mathrm{DPPH}{ }^{+}$in $100 \mathrm{ml}$ methanol. Assays were carried out according to the methodology of Sharma et al. (1998).

b) The mixture was detected with ceric sulphate (Ce $\left.\left(\mathrm{SO}_{4}\right)_{2}\right)$ reagents. This was prepared by dissolving $12 \mathrm{~g}$ ceric sulphate, $22.5 \mathrm{~g}$ sulphuric acid in $350 \mathrm{~g}$ of cut ice (Sherman \& Fried, 2003).

c) Flavonoids and hydroxycinnamic acids detection were according to Sharma et al. (1998). Using a UV light chamber 220v (Edmund optics Inc. Barrington, $\mathrm{H}$ ), USA).

Quantitative evaluation of the free-radical scavenging and antioxidant activity $\mathrm{DPPH} \mathrm{H}^{+}$free radical scavenging activity assays

Determination of scavenging stable $\mathrm{DPPH}^{+}$free radicals was a very fast method to evaluate the antioxidant activity of the extracts, by measurement of the decrease in the absorbance of DPPH at $517 \mathrm{~nm}$. The method used was described by Hatano et al. (1988) with some modifications. Into $4.5 \mathrm{ml}$ methanol were added $0.5 \mathrm{ml}$ of the $\mathrm{DPPH}^{+}$solution (about $0.5 \mathrm{~g} \mathrm{l}^{-1}$ ) and $0.1 \mathrm{ml}$ of cheese alcoholic extract. Standards such as trolox; caffeic acid; $t \mathrm{BHQ}$ and catechin were used as a reference index to 
Table 1. Effect of feeding system on the concentration of total polyphenol content and bioactive polyphenolic compounds in four kinds of soft goats' milk cheese extracts $(\mathrm{mg} / \mathrm{kg})$

Values are means \pm SD for $n=5$

Kinds of cheese

\begin{tabular}{|c|c|c|c|c|c|c|}
\hline GR & GP & IR & IP & FS & TT & FS*TT \\
\hline $780^{a} \pm 120$ & $300^{b} \pm 40$ & $50^{\mathrm{C}} \pm 1 \cdot 0$ & $60^{c} \pm 14$ & $* *$ & $*$ & $*$ \\
\hline $14^{\mathrm{a}} \pm 2 \cdot 0$ & $6 \cdot 5^{b} \pm 1 \cdot 0$ & ND & ND & $* *$ & $* *$ & $* *$ \\
\hline $119^{a} \pm 47$ & $11^{b} \pm 6 \cdot 0$ & $53^{\mathrm{ab}} \pm 6 \cdot 0$ & $97^{\mathrm{a}} \pm 32$ & NS & NS & $*$ \\
\hline $61 \pm 3 \cdot 0$ & ND & $165 \pm 8 \cdot 0$ & $10 \pm 5 \cdot 0$ & NS & $*$ & NS \\
\hline $0 \cdot 23 \pm 0 \cdot 1$ & $0 \cdot 09 \pm 0 \cdot 1$ & $0 \cdot 16 \pm 0 \cdot 1$ & $0 \cdot 16 \pm 0 \cdot 1$ & NS & NS & NS \\
\hline $4 \cdot 2 \pm 0 \cdot 3$ & $2 \cdot 4 \pm 0 \cdot 2$ & ND & $3 \cdot 0 \pm 0 \cdot 9$ & NS & NS & NS \\
\hline
\end{tabular}

$\mathrm{GR}=$ cheese made from grazing goats' raw milk, GP=cheese made from grazing goats' pasteurized milk, IR=cheese made from indoor goats' raw milk, $\mathrm{IP}=$ cheese made from indoor goats' pasteurized milk. a,b,c means with different letters indicate differences $(P<0 \cdot 05)$ between columns. FS: Feeding system. TT: Thermal treatment. FS*TT: Interaction between feeding system and thermal treatment. ${ }^{*} P<0 \cdot 05, * * P<0 \cdot 0001$. NS $=$ No statistically significance. $\mathrm{ND}=$ Not detected.

determine radical scavenging capacity of the samples. The activity of each standard was calculated as:

Radical scavenging activity $(\%)=\left(\left(A t_{0}-A t_{\text {end }}\right) / A t_{0}\right) * 100$,

where $A t_{0}$ is the start absorbance at time zero and $A t_{\text {end }}$ is the final absorbance after $60 \mathrm{~min}$. Five parallel cheeses per treatment were analysed by triplicate.

\section{Radical scavenging activity by ABTS $^{+}$}

Radical scavenging activity by ABTS (2, 2'-azino-bis [3ethylbenzthiazoline-6-sulphonic acid]) radical cation was made according with Kuskoski et al. (2005) and Turkmen et al. (2006). Standards as Trolox, $t B H Q$, caffeic acid and quercetin were used as an index reference data. All determinations were carried out three times for the 20 samples (five parallel cheeses per treatment). The percentage inhibition of absorbance at $730 \mathrm{~nm}$ was calculated according to the equation of Re et al. (1999).

\section{Determination of antioxidant activity by liposome oxidation method}

Liposome preparation and lipid stress unilamellar small liposome were prepared as described by Tsuda et al. (1994). Briefly, $10 \mathrm{~g}$ soybean phosphatidylcholine was dissolved in methanol $(10 \mathrm{ml})$. Methanol was then evaporated to obtain a fine lipid layer. These lipids were resuspended in $10 \mathrm{ml}$ phosphate buffer saline $(137 \mathrm{~mm}-$ $\mathrm{NaCL}, 10 \mathrm{~mm}$-phosphate, 2.7 mm-KCL, pH 7.4) by vortex agitation, to a final lipid concentration of $1 \mathrm{mg} / \mathrm{ml}$, and treated with an ultrasound Branson 8210 (Branson Ultrasonic Corporation, CT, USA) for $10 \mathrm{~min}$. Then solu-

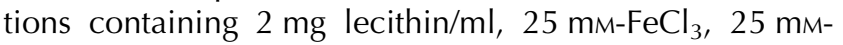
$\mathrm{H}_{2} \mathrm{O}_{2}, 25 \mathrm{~m}$-ascorbic acid and alcoholic cheese extracts
$(0.5 \mathrm{mg} / \mathrm{ml})$ were prepared following the method of Siddhuraju et al. (2002). The mixture was incubated for $2 \mathrm{~h}$ at $37^{\circ} \mathrm{C}$ by the thiobarbituric acid (TBA) method. The absorbance of the sample was read at $532 \mathrm{~nm}$ (Spectronic GENESYS 5 and 2 UV-Vis, Thermo Fisher Scientific, Inc, USA) against a blank which contained all reagents except lecithin. Five parallel cheeses per treatment were analysed in triplicate.

\section{Statistical analysis}

The statistical model fixed effects with interaction and variance analysis in a $2 \times 2$ factorial arrangement, with two feeding treatments ( $\mathrm{A}$ and $\mathrm{B}$ ) and two milk processes (raw and pasteurized). Results are reported as means \pm standard deviation. Differences between the groups were assessed by the Tukey's test. Data were analysed by General Lineal Model using SAS program (version 8.2, Cary, NC, USA). We considered the differences between the means to be significant if $P<0 \cdot 05$.

\section{Results and Discussion}

\section{Total phenol in the cheese extracts}

The present study, indicated that polyphenol content were affected by animal feeding $(P<0.0001)$ and heat treatment of milk $(P<0 \cdot 0008)$. The total polyphenol content was higher $(P<0.05)$ in GR in relation to GP, IR and IP cheese (Table 1). Pasteurization negatively influenced total polyphenol concentration, due to the possibility of denaturation of phenol content and amino acid catabolism (De Feo et al. 2006), and the higher values in GR and GP are related to the higher consumption of polyphenols during grazing (O'connell \& Fox, 2001). 
Table 2. Effect of feeding system on the free-radical scavenging of four kinds of goats' milk cheese extracts (\%)

Values are means \pm SD for $n=5$

Kinds of cheese

\begin{tabular}{lllllllll}
\cline { 2 - 5 } \cline { 6 - 7 } Antioxidant essay & GR & GP & IR & IP & & FS & TT & FS*TT \\
DPPH $^{+}$Radical & $26 \cdot 9 \pm 1 \cdot 2$ & $24 \cdot 1 \pm 4 \cdot 0$ & $16 \cdot 5 \pm 8 \cdot 5$ & $15 \cdot 2 \pm 5 \cdot 5$ & $*$ & NS & NS \\
ABTS $^{+}$Radical & $33 \cdot 3 \pm 5 \cdot 6$ & $24 \cdot 9 \pm 4 \cdot 0$ & $16 \cdot 5 \pm 8 \cdot 3$ & $15 \cdot 2 \pm 5 \cdot 6$ & $* *$ & NS & NS \\
Liposome & $31 \cdot 7 \pm 12 \cdot 8$ & $55 \cdot 6 \pm 4 \cdot 0$ & $47 \cdot 1 \pm 4 \cdot 0$ & $56 \cdot 4 \pm 6 \cdot 2$ & NS & NS & NS
\end{tabular}

\begin{tabular}{lrrr}
\multicolumn{4}{c}{ Standards } \\
\hline Trolox & \multicolumn{1}{c}{ tBHQ } & Caffeic acid & Quercetin \\
$99 \cdot 6 \pm 0 \cdot 6$ & $93 \pm 5 \cdot 0$ & $71 \pm 2 \cdot 5$ & $92 \cdot 2 \pm 2 \cdot 0$ \\
$99 \cdot 5 \pm 1 \cdot 3$ & $94 \cdot 3 \pm 0 \cdot 5$ & $75 \cdot 2 \pm 9 \cdot 3$ & $95 \cdot 2 \pm 4 \cdot 9$ \\
$69 \cdot 1 \pm 0 \cdot 1$ & $61 \cdot 9 \pm 5 \cdot 6$ & $64 \cdot 3 \pm 7 \cdot 5$ & $64 \cdot 4 \pm 2 \cdot 2$
\end{tabular}

$\mathrm{GR}=$ cheese made from grazing goats' raw milk, GP= cheese made from grazing goats' pasteurized milk, IR=cheese made from indoor goats' raw milk, $\mathrm{IP}=$ cheese made from indoor goats' pasteurized milk. Trolox=6-hydroxy-2, 5, 7, 8-tetramethylchroman-2-carboxylic acid. $t \mathrm{BHQ}=\mathrm{Tert}-\mathrm{butylhy}$ droquinone, $\mathrm{DPPH}^{+}=\left(1,1\right.$-diphenyl-2-picrylhydrazyl), $\mathrm{ABTS}^{+}=\mathrm{ABTS}[2,2$-azinobis-(3-ethylbenzothiazoline-6-sulphonic acid)]. FS: Feeding system. TT: Thermal treatment. FS*TT: Interaction between feeding system and thermal treatment. ${ }^{*} P<0 \cdot 05, * * P<0 \cdot 0001$. NS $=$ No statistically significance.

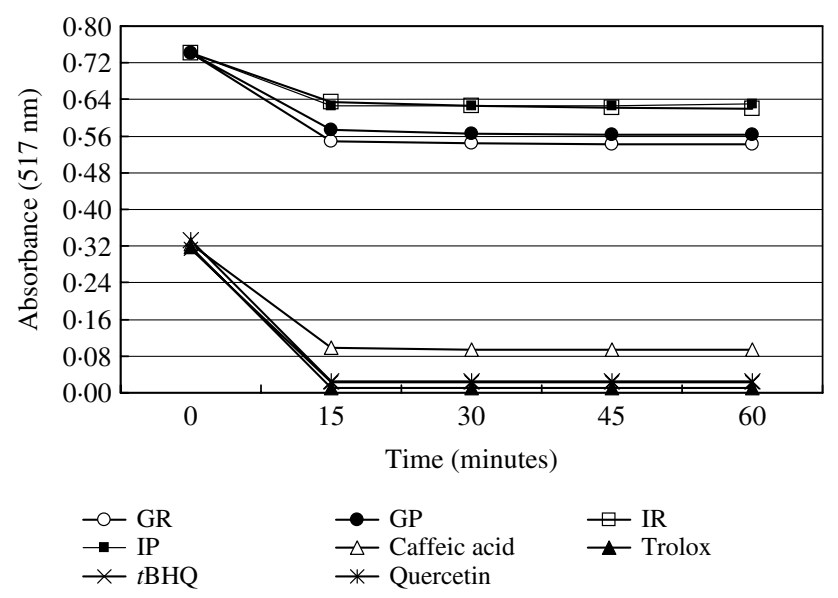

Fig. 2. Kinetic of $\mathrm{DPPH}^{+}$free-radical scavenging in 4 kinds of soft goats' milk cheese extracts. GR=cheese made from grazing goats' raw milk, GP=cheese made from grazing goats' pasteurized milk, $I R=$ cheese made from indoor goats' raw milk, $I P=$ cheese made from indoor goats' pasteurized milk. Trolox= 6-hydroxy-2, 5, 7, 8-tetramethylchroman-2-carboxylic acid. $t \mathrm{BHQ}=$ Ter-butylhydroquinone.

\section{Bioactive polyphenolic compounds in cheese extracts}

Hydroxycinnamic acids in this assay exhibit a detectable antioxidant activity, caffeic acid contents only appeared in GR and GP cheeses; this was probably due to a diet rich in phenolic compounds coming from the vegetation grazed by goats. However in IR and IP cheeses this compound was not detected, possibly because this hydroxycinnamic acid is sensitive to the pasteurization (Table 2). Besides, ferulic acid was altered by the pasteurization treatment $(P<0 \cdot 05)$, where IR cheese showed higher concentration of ferulic acid, possibly because the concentrate grain consumed by stall goats contained corn, a cereal rich in these hydroxycinnamic acids. Chlorogenic acid concentrations were altered by the animal feeding system and the pasteurization treatment; unclear effects are due to possibly not only the detrimental thermal effect but also the production de novo antioxidants metabolites product of Maillard reaction (Calligaris et al. 2004). On the other hand, catechin

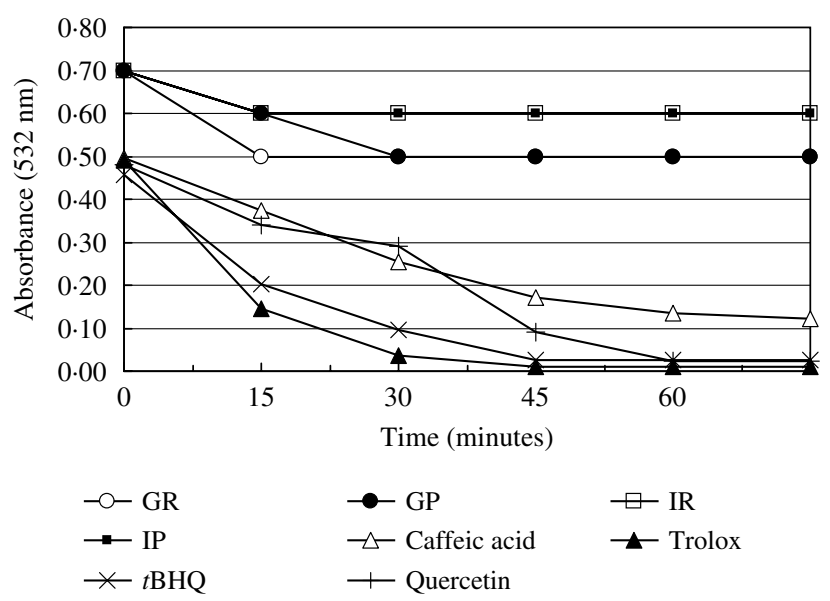

Fig. 3. Kinetic of $\mathrm{ABTS}^{+}$free-radical scavenging in 4 kinds of soft goats' milk cheese extracts. For abbreviations see Fig. 2.

showed a lower average concentration, probably because milk based products represent a very complex matrix; where strong catechin-protein interactions may occur and interfere directly with accumulated catechin determination by significantly reducing the analytical recovery (Siebert et al. 1996). Research of Ferruzzi \& Green (2006), suggests the application of short-time pepsin treatment in an enzymatic assisted extraction, to release the catechins in beverages combined with milk which contain active ingredients as tea catechins, increases the recovery of total catechins and their isomers from 20 to $50 \%$. Otherwise, De Feo et al. reported values of quercetin in milk of $0.012 \mathrm{~g} \mathrm{I}^{-1}$ (De Feo et al. 2006). Cheese processing in the current investigation could alter the quercetin and other flavonoids solubility leading to some losses, because they can react in lipid and aqueous phases; acting as radical scavengers and metal ion binders (Zulueta et al. 2009).

\section{Qualitative evaluation of the free-radical scavenging and bioactive polyphenols by TLC}

Thin layer chromatography demonstrated that GR and GP cheeses had the maximum antioxidant activity and 
concentration of phenolic compounds (Fig. 1). This chemical group was exposed by specific developers, their concentration increased in cheeses made with raw milk under grazing management. Sharma et al. (1998) showed that this activity can be related to the presence of gallic acid, catechin, epicatechin, cinnamic acid, p-coumaric acid and ferulic acid. These results seen to be similar to those reported by Ahmad \& Beg (2001), who evaluated 45 medicinal plants by TLC, finding that this activity was associated with these metabolites. The chromatograms developed with Vanilline- $\mathrm{H}_{2} \mathrm{SO}_{4}$, displayed colours belonging to catequine and quercetin compounds; flavonoids with high antioxidant dynamism, largely present in GR and GP cheeses; even though, these were also found in cheeses from indoor management.

\section{Free-radical scavenging and quantitative antioxidant activity}

$D P P H$ free radical scavenging activity. Free radical scavenging activity is important due to the protection against damage caused by free radicals in food and in living systems. DPPH method has been successfully tested measuring the total antioxidative capacity of milk (Smet et al. 2008). Lower values of these activities in cheese, are possibly due to the metabolism of ruminants in certain compounds with antioxidant activity $\left(\mathrm{O}^{\prime}\right.$ connell \& Fox, 2001). During the kinetics of the quantitative antioxidant activity with DPPH, GR established at $15 \mathrm{~min}$ the highest antioxidant activity. On the other hand, GP was the second best cheese with an absorbance of $0.574 \mathrm{~nm}$ at $15 \mathrm{~min}$, and a final value at $60 \mathrm{~min}$ of $0.563 \mathrm{~nm}$ (Fig. 2). These differences are due to pasteurized milk containing higher serum proteins and less albumin, when a denaturation due to heat stress occurs as has been demonstrated by Zulueta et al. (2009) who tested commercial milks in Italy to evaluate the total antioxidant activity.

Radical scavenging activity by ABTS. In the analysis of the kinetic of free radicals scavenging by ABTS, GR cheeses showed at $15 \mathrm{~min}$ the highest free radical scavenging (Fig. 3). This result could be due to the fact that pasteurization process can influence the formation of compounds that have antioxidant capacity during the Maillard reaction (Calligaris et al. 2004). Chen et al. (2003) evaluated the antioxidant capacity of bovine milk using the $\mathrm{ABTS}^{+}$radical, and found a significant antioxidant capacity, in agreement with the current report. Likewise, Wegrzyn et al. (2008) evaluated the effects of fortifying apple polyphenol extract into milk drinks. The oxidation and loss of antioxidant capacity of apple polyphenols limited the work when the flavonoid content is high; demonstrating that the use of $200 \mathrm{mg}$ apple polyphenol per $100 \mathrm{ml}$ milk, permitted a physical stability and antioxidant capacity of the beverage in relation to control milk (zero mg apple polyphenols/ $100 \mathrm{ml}$ ) during storage and thermal processing.

\section{Antioxidant activity on liposome oxidation}

In this cell model, the deleterious effect of pasteurization and the effects of animal feeding seem not to influence the radical scavenging. The synergism between antioxidant compounds as well as the production of de novo antioxidant metabolite products can explain this effect (Calligaris et al. 2004; Smet et al. 2008). Also, the content of natural potentially antioxidant aminoacids like tyrosine, tryptophan, histidine, lisine and methionine can influence the final antioxidant capacity (Zulueta et al. 2009). According to this study, Cervato et al. (1999) evaluated casein fractions antioxidant capacity in liposomal models. All caseins fractions were able to inhibit peroxidation by modifying the $\mathrm{Fe} 2^{+} / \mathrm{Fe} 3^{+}$equilibrium and thus inhibit lipid peroxidation of milk matrix. Though, liposome model did not follow the same patterns as $\mathrm{DPPH}^{+}$and $\mathrm{ABTS}^{+}$antioxidant essays, complementarity of the results demonstrate the capability of cheese extracts to inhibit free radical damage.

Present results showed that soft goats' cheese antioxidant activity can be modified by the animals feeding system. Grazing management represents a better option than indoor feeding to produce a healthy profile of bioactive compounds; providing an increase of total polyphenol, hydroxycinnamic acids and flavonoid concentrations. Pasteurization did have a significant effect on these metabolites, and diminished total polyphenol concentration. More research is needed to elucidate the potential of soft goats' cheese as a functional food.

Mario Cuchillo Hilario thanks the Consejo Nacional de Ciencia y Tecnología (CONACYT) for his Master grant.

\section{References}

Ahmad I \& Beg AZ 2001 Antimicrobial and phytochemical studies on 45 Indian medicinal plants against multi-drug resistant human pathogens. Journal of Ethnopharmacology 74 113-123

Calligaris S, Manzocco L, Anese M \& Nicoli MC 2004 Effect of heattreatment on the antioxidant and pro-oxidant activity of milk. International Dairy Journal 14 421-427

Carnachan SM \& Harris PJ 2000 Ferulic acid is bound to the primary cell walls of all gymnosperm families. Biochemical Systematics and Ecology 28 865-879

Cervato G, Cazzola R \& Cestaro B 1999 Studies on the antioxidant activity of milk caseins. International Journal of Food Sciences and Nutrition 50 291-296

Chen J, Lindmark-Månsson H, Gorton L \& Åkesson B 2003 Antioxidant capacity of bovine milk as assayed by spectrophotometric and amperometric methods. International Dairy Journal 13 927-935

Cuchillo HM, Puga DC, Galina MA \& Pérez-Gil RF 2009a Influence of semiarid summer browsing on chemical composition in goat's milk cheeses. Tropical and Subtropical Agroecosystems 11 25-28

Cuchillo HM, Puga DC, Wrage N \& Pérez-Gíl RF 2009b Feeding regime and pasteurization impact on gross chemical composition and fatty 
acids content of goats' milk and soft cheese. Asian-Australasian Journal of Animal Sciences Submitted.

De Feo V, Quaranta E, Fedele V, Claps S, Rubino R \& Pizza C 2006 Flavonoids and terpenoids in goat milk in relation to forage intake. Italian Journal of Food Science $\mathbf{1}$ 85-92

Ferruzzi MG \& Green RJ 2006 Analysis of catechins from milk-tea beverages by enzyme assisted extraction followed by high performance liquid chromatography. Food Chemistry 99 484-491

Galina MA, Osnaya F, Cuchillo HM \& Haenlein GFW 2007 Cheese quality from milk of grazing or indoor fed Zebu cows and Alpine crossbred goats. Small Ruminant Research 71 264-272

Halliwell B 1996 Antioxidants in human health and disease. Annual Review of Nutrition 16 33-50

Hatano T, Kagawa H, Yasuhara T \& Okuda T 1988 Two new flavonoids and other constituents in liquorice root: their relative astringency and radical scavenging effects. Chemical and Pharmaceutical Bulletin 36 1090-2097

Kuskoski EM, Asuero AG, Troncoso AM, Mancini-Filho J \& Fett R 2005 Aplicación de diversos métodos químicos para determinar actividad antioxidante en pulpa de frutos. Ciência e Tecnologia de Alimentos 25 726-732

Middleton E, Kandaswami C \& Theoharides TC 2000 The effects of plant flavonoids on mammalian cells: implications for inflammation, heart disease, and cancer. Pharmacological Reviews 52 673-751

O'Connell JE \& Fox PF 2001 Significance and applications of phenolic compounds in the production and quality of milk and dairy products: a review. International Dairy Journal 11 103-120

Puga DC, Cuchillo HM \& Pérez-Gil RF 2009a Effect of feeding management and seasonal variation on fatty acid composition of Mexican soft raw goats' milk cheese. Italian Journal of Animal Science 8 402-404

Puga DC, Galina HM, Bonilla CA, Cuchillo HM, Montaño BS, Castillo DR, Villareal E \& Pérez-Gil RF 2009b Effect of feeding management on the nutritional composition of Mexican artisan soft cheese made with raw or pasteurized goats' milk. Indian Journal of Animal Science 79 321-326.

Re R, Pellegrini N, Proteggente A, Pannala A, Yang M \& Rice-Evans C 1999 Antioxidant activity applying an improved ABTS radical cation decolorization assay. Free Radical Biology and Medicine 26 1231-1237
Ruiz-Terán F, Medrano-Martínez A \& Navarro-Ocaña A 2008 Antioxidant and free radical scavenging activities of plant extracts used in traditional medicine in Mexico. African Journal of Biotechnology 7 1886-1893

Sanz Sampelayo MR, Chilliard Y, Schmidely P \& Boza J 2007 Influence of type of diet on the fat constituents of goat and sheep milk. Small Ruminant Research 68 42-63

Sharma OP, Bhat TK \& Singh B 1998 Thin-layer chromatography of gallic acid, methyl gallate, pyrogallol, phloroglucinol, catechol, resorcinol, hydroquinone, catechin, epicatechin, cinnamic acid, p-coumaric acid, ferulic acid and tannic acid. Journal of Chromatography A 822 $167-171$

Sherman J \& Fried B 2003 Handbook of thin-layer chromatography. 3rd Edn. New York, NY, USA: Marcel Dekker Inc.

Siddhuraju P, Mohan PS \& Becker K 2002 Studies on the antioxidant activity of Indian Laburnum (Cassia fistula L.): a preliminary assessment of crude extracts from stem bark, leaves, flowers and fruit pulp. Food Chemistry 79 61-67

Siebert KJ, Troukhanova NV \& Lynn PY 1996 Nature of polyphenolprotein interactions. Journal of Agricultural and Food Chemistry 44 80-85

Smet K, Raes K, De Block J, Herman L, Dewettinck K \& Coudijzer K 2008 A change in antioxidative capacity as a measure of onset to oxidation in pasteurized milk. International Dairy Journal 18 520-530

Taga M, Miller E \& Pratt D 1984 Chia seeds as a source of natural lipid antioxidants. Journal of the American Oil Chemists Society $\mathbf{6 1}$ 928-931

Tsuda T, Sugaya A, Yong Zhen L, Katoh K, Tanaka H, Kawazura H, Sugaya E, Kusai M \& Kohno M 1994 Radical scavenger effect of Boschniakia rossica. Journal of Ethnopharmacology 41 85-90

Turkmen N, Sari F \& Velioglu YS 2006 Effects of extraction solvents on concentration and antioxidant activity of black and black mate tea polyphenols determined by ferrous tartrate and Folin-Ciocalteu methods. Food Chemistry 99 835-841

Wegrzyn TF, Farr JM, Hunter DC, Au J, Wohlers W, Skinner MA, Stanley RA \& Sun-Waterhouse D 2008 Stability of antioxidants in an apple polyphenol-milk model system. Food Chemistry 109 310-318

Zulueta A, Maurizi A, Frígola A, Esteve MJ, Coli R \& Burini G 2009 Antioxidant capacity of cow milk, whey and deproteinized milk. International Dairy Journal 19 380-385 